\title{
Applications of Ferrocenium Salts in Organic Synthesis
}

\author{
Štefan Toma* \\ Radovan Šebesta* \\ Department of Organic Chemistry, Faculty of Natural Sciences, \\ Comenius University in Bratislava, Mlynska dolina $\mathrm{CH}-2,84215$, \\ Bratislava, Slovakia \\ toma@fns.uniba.sk \\ radovan.sebesta@fns.uniba.sk
}

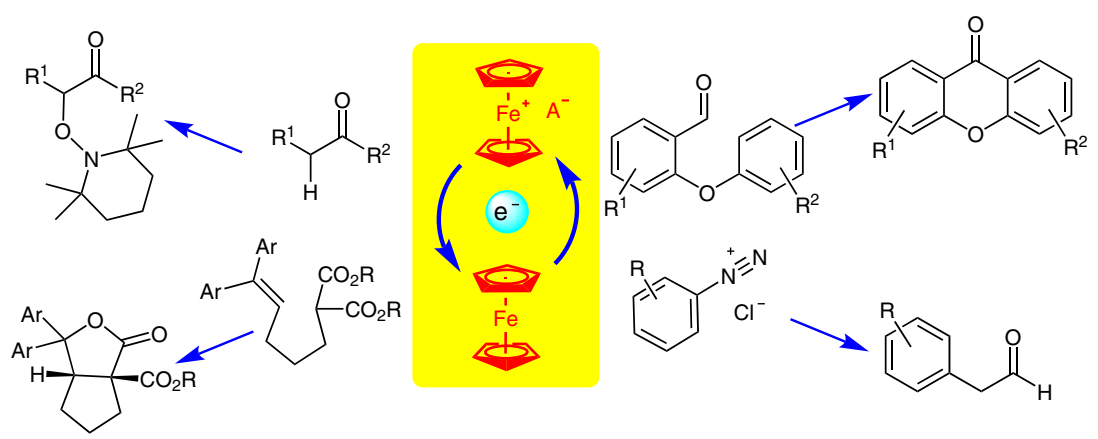

Received: 27.02 .2015

Accepted after revision: 09.04.2015

Published online: 23.04 .2015

DOI: 10.1055/s-0034-1379920; Art ID: ss-2015-e0130-

Abstract Ferrocenium salts can be easily obtained from ferrocene by either synthetic preparation or in situ reaction. The ferrocenium ion can act as a one-electron oxidant and thus initiate or promote a range of radical processes. Ferrocene itself can donate electrons to suitable substrates, resulting in useful transformations. Ferrocenium salts can also act as mild Lewis acids. This paper highlights various uses of ferrocenium ions in organic reactions.

Introduction

Ferrocenium Salts as Lewis Acids

Ferrocenium Salts as One-Electron Oxidants

Ferrocene as an Electron Donor

Catalysis with Other Ferrocenium Derivatives

Conclusions

Key words catalysis, organometallic reagents, cations, ferrocene, ferrocenium

\section{Introduction}

Ferrocene and its derivatives are among the most important organometallic compounds. The ferrocene framework features in many chiral and achiral catalysts, ${ }^{1}$ materials, and even some potential medicines. ${ }^{2}$ The ability of ferrocene to undergo reversible one-electron oxidation to the ferrocenium cation is important for many applications of ferrocene and its derivatives in electrochemistry. Nowadays, the ferrocene/ferrocenium cation couple can serves as a reference material in cyclic voltammetry. ${ }^{3}$ The redox potential of $\mathrm{Fc}^{+} / \mathrm{Fc}$ is $0.64 \mathrm{~V}$ vs. the standard hydrogen electrode. ${ }^{4}$ Furthermore, the oxidation potential of ferrocenium ion can be modified by altering the substitution on the cyclopentadienyl rings. With respect to its structure, the question can be asked: is the ferrocenium ion a cation radical or just a cation? The question was answered over 50 years ago by quantum chemical calculations of iron bonding in the ferrocene molecule. According to the calculations, there are two electrons located in the hybridized iron orbit$\mathrm{al}$, and one electron oxidation must, therefore, result in the cation radical (Scheme 1$){ }^{5}$

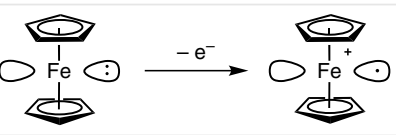

Scheme 1

A more subtle look at molecular orbitals confirms this notion. The ferrocenium ion is in its ground state a low-spin $\mathrm{d}^{5}$ complex with one unpaired electron. Its frontier-orbital configuration is $\left(e_{2 g}\right)^{3}\left(a^{\prime}{ }_{1 g}\right)^{2}$. This description is supported by band intensities of the photoelectron spectrum, which indicate that the first ionization results from an $e_{2}$ molecular orbital. Furthermore, EPR spectra and the magnetic moment of ferrocenium ion also support the orbitally degenerate ground state ${ }^{2} \mathrm{E}_{2 \mathrm{~g} .}{ }^{6}$

Ferrocenium salts are typically a dark blue color and they are paramagnetic. Soon after the discovery of ferrocene, its easy oxidation to the ferrocenium cation by iron(III) chloride or benzoquinone was described. ${ }^{7}$ Thus, the first isolated ferrocenium salt was ferrocenium tetrachloroferrate. The ferrocenium ion can be prepared with various counterions, such as tetrafluoroborate $\left(\mathrm{BF}_{4}\right)$, hexafluorophosphate $\left(\mathrm{PF}_{6}\right)$, hexafluoroantimonate $\left(\mathrm{SbF}_{6}\right)$, or tetraphenylborate $\left(\mathrm{BPh}_{4}\right)$. Ferrocenium hexafluorophosphate $\left(\mathrm{Cp}_{2} \mathrm{Fe}^{+} \mathrm{PF}_{6}{ }^{-}\right)$and ferrocenium tetrafluoroborate $\left(\mathrm{Cp}_{2} \mathrm{Fe}^{+} \mathrm{BF}_{4}^{-}\right)$ are the most commonly employed ferrocenium salts in organic synthesis; they are also commercially available. Ferrocenium hexafluorophosphate can be efficiently prepared by oxidation of ferrocene with iron(III) chloride and treating the resulting solution with ammonium hexafluorophos- 
phate. $^{8}$ The synthesis of ferrocenium tetrafluoroborate involves the oxidation of ferrocene with $p$-benzoquinone in the presence of tetrafluoroboric acid-diethyl ether complex. ${ }^{9}$ Several methods have been described for the preparation of substituted ferrocenium salts. Acetylferrocenium tetrafluoroborate is prepared by the oxidation of acetylferrocene with dry silver(I) tetrafluoroborate in diethyl ether. ${ }^{10}$ Ferrocenium salts derived from 1-bromo-, and 1,1'dibromoferrocene, as well as 1-ethyl-, and 1,1'-diethylferrocene, with the trifluoromethanesulfonimide anion $\left(\mathrm{NTf}_{2}\right)$ were prepared by oxidation of the corresponding starting materials by dry silver(I) trifluoromethanesulfonimideacetonitrile complex. ${ }^{11}$ Very thorough investigation of the oxidation of ferrocene derivatives by benzoquinone, 2,3-dichloro-5,6-dicyano-1,4-benzoquinone, and 2,2,6,6-tetramethylpiperidin-1-oxyl (TEMPO) was performed by Jahn and co-workers. ${ }^{12}$ They found that 2,3-dichloro-5,6-dicyano-1,4-benzoquinone is preferred for the oxidation of ferrocene derivatives with strong electron-attracting groups, like $\mathrm{Bz}, \mathrm{CO}_{2} i-\mathrm{Pr}, \mathrm{POPh}_{2}$, etc. The prepared ferrocenium cations were isolated as the hexafluorophosphate salts and they were stable in acetonitrile or dichloromethane, but slowly reduced to the starting ferrocene derivatives in ethereal solvents, $\mathrm{N}, \mathrm{N}$-dimethylformamide, or dimethyl sulfoxide. Ferrocenium hexafluorophosphate salts are poorly soluble in apolar solvents, and for applications in such solvents it is advisable to prepare ferrocenium salts with more lipo- philic anions, such as trifluoromethanesulfonimide or tetrakis[3,5-bis(trifluoromethyl)phenyl]borate (BARF). ${ }^{13}$ 1Amino- and 1,1'-diamino-functionalized ferrocenium salts have been described. ${ }^{14}$ Ferrocenyl dendrimers have been synthesized that can be used as multi-electron redox agents. ${ }^{15}$

Ferrocenium salts take part in various transformations within the concept of redox catalysis. Interestingly, ferrocenium ions can participate in both branches of redox catalysis, hole catalysis and electron catalysis. ${ }^{16}$ Ferrocene can initiate various transformations by injection of an electron to the starting material. On the other hand, the ferrocenium ion can start a catalytic sequence by removal of the electron from an appropriate substrate. To the best of our knowledge, the applications of ferrocenium salts in organic synthesis have not yet been reviewed, only their application as redox agents in organometallic chemistry. ${ }^{4}$ Apart from their redox properties and accompanying use in various oxidoreduction processes, ferrocenium salts can act also as weak Lewis acids, although there are only a few examples of this application. This review gives an overview of applications of ferrocenium ions in organic synthesis.

With respect to terminology, terms 'ferricenium' or 'ferricinium cation' were sometimes used in older literature; they refer to the same compound, that is the ferrocenium cation. The term ferrocenium is preferable and in this review it shall be used exclusively.

\section{Biographical Sketches}
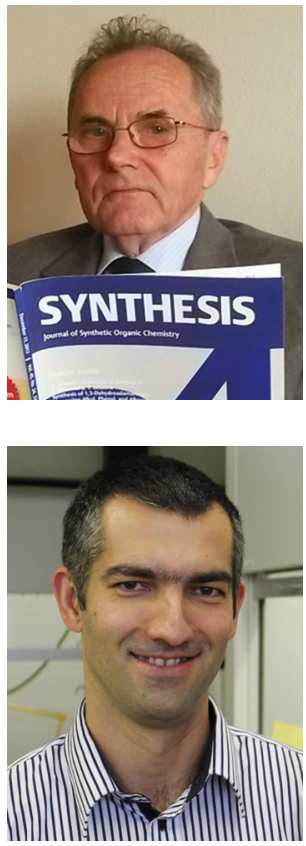

Professor Štefan Toma graduated from Comenius University in Bratislava (1960) and also gained Ph.D. (1965) and D.Sc. (1982) degrees from the same university. From 1983, he was a full professor of organic chemistry at Comenius University in Bratislava and he is now Profes-

Radovan Šebesta, born in 1975, studied chemistry at the Faculty of Natural Sciences, Comenius University in Bratislava, where he received a Ph.D. in organic chemistry in 2002. He carried out postdoctoral research with Prof. Dieter Seebach at ETH Zürich, working on the sor Emeritus. Immediately after graduation he began research in ferrocene chemistry, later, after a postdoctoral stay with Professor P. L. Pauson (1970-1971), he also became interested in the synthesis and reactivity of dienetricarbonyliron complexes and benzenetricarbonylchromi-

synthesis of $\beta$-amino acids and peptides. He then worked with Prof. Ben L. Feringa at Groningen University on asymmetric catalysis with phosphoramidites. In 2005, he joined Prof. Stefan Toma's group at the Comenius University as an Assistant Professor. Since 2008, he um complexes. He has made contributions in sonochemistry and microwave chemistry. In years, he has been heavily engaged in the study of stereoselective reactions catalyzed by transitional-metal complexes or organocatalysts using an ionic liquid as the solvent.

has been an Associate Professor of organic chemistry; in 2014 he obtained a D.Sc. from Comenius University. His research interests include the development of new asymmetric catalytic transformations with ferrocene catalysts or organocatalysts. 


\section{Ferrocenium Salts as Lewis Acids}

Some researchers consider the ferrocenium ion to be non-Lewis acidic cation as it is unlikely that it will form a stable 19-electron complex upon coordination with a Lewis base. However, there are several reports in which the ferrocenium ion is thought to act as a weak Lewis acid. One of the first examples is the ferrocenium ion catalyzed DielsAlder reaction. ${ }^{17}$ It was shown that ferrocenium hexafluorophosphate was able to increase the rate of the reaction of both cyclic and acyclic dienes with $\alpha, \beta$-unsaturated aldehydes and ketones. Modest rate enhancement of the DielsAlder reaction was also noted when ferrocenium ions were derived from [4]-ferrocenophane. ${ }^{18}$

Ferrocenium hexafluorophosphate can accelerate the solvent-free cyanosilylation of carbonyl compounds; aromatic aldehydes and ketones $\mathbf{1}$ afforded the corresponding silylated cyanohydrins 2 (Scheme 2 ). ${ }^{19}$

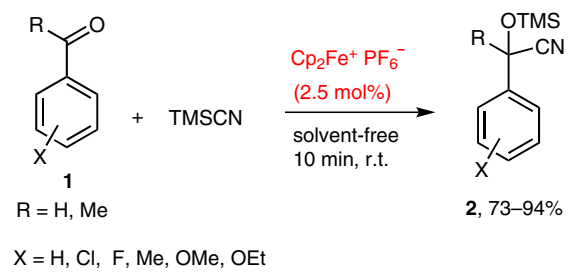

Scheme 2

Cyanosilylations also proceed well with naphthalene-2carbaldehyde (85\%), furan-2-carbaldehyde (65\%), thiophene-2-carbaldehyde (68\%), cinnamaldehyde (70\%), and 3-phenylpropanal (74\%) and with other aliphatic aldehydes (75-92\%). Under the same conditions, cyanosilylation was successful with various ketones. It was proposed that the ferrocenium ion acts as a Lewis acid in these reactions; its function is to polarize the carbonyl functionality in the substrates.

In the Strecker reaction of aldehydes and ketones with aromatic amines 3 and trimethylsilyl cyanide, ${ }^{20}$ a small amount of ferrocenium hexafluorophosphate accelerated the reaction with aliphatic aldehydes as well as aliphatic ketones; the corresponding amino nitriles $\mathbf{4}$ were obtained in high yields (Scheme 3).

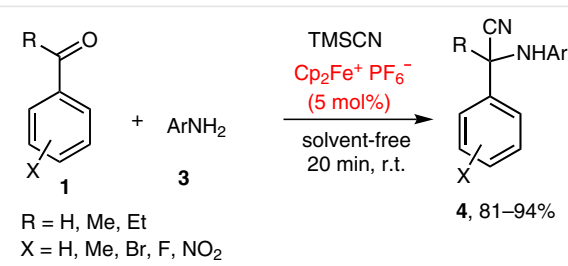

Scheme 3
Another application of a ferrocenium salt as a Lewis acidic catalyst is in the aminolysis of epoxides (Scheme 4). ${ }^{21}$ Cyclopentene and cyclohexene oxides $\mathbf{5}$ underwent ring opening with several anilines in a reaction catalyzed by 5 mol\% of ferrocenium tetrafluoroborate; the corresponding amino alcohols $\mathbf{6}$ were obtained in good yields even at lower temperatures.

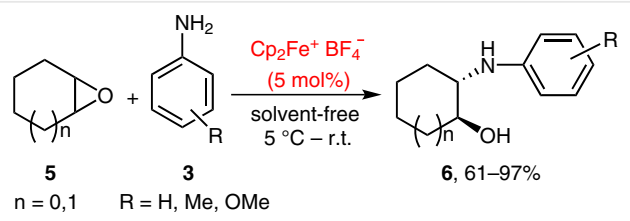

Scheme 4

On the other hand, reactions with aliphatic amines were carried out at $60{ }^{\circ} \mathrm{C}$ and longer reaction times were, generally, necessary. Competitive experiments were performed using piperidine and aniline as the amines and an interesting temperature effect was observed. The reaction at room temperature gave a mixture of piperidine- and aniline-derived products in 96:4 ratio, but the same reaction at $60{ }^{\circ} \mathrm{C}$ gave a mixture with $87: 13$ ratio. This reaction worked well with other epoxides, even with epichlorohydrin (7), which afforded the expected amino alcohol 8 accompanied by a smaller amount of product $\mathbf{9}$. Interestingly, no substitution of chlorine was observed (Scheme 5).

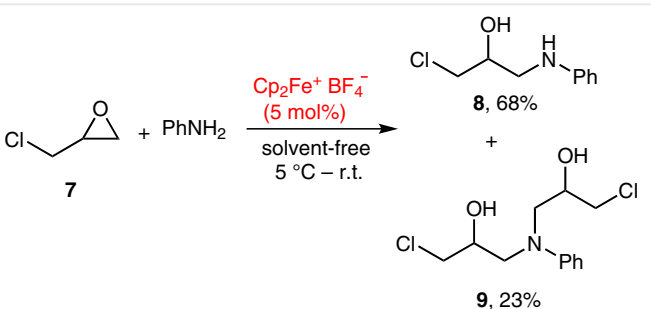

Scheme 5

The ring opening of epoxides $\mathbf{1 0}$ with alcohols can be catalyzed by ferrocenium salts. ${ }^{22}$ Other Lewis acids, such as iron(III) chloride, indium(III) chloride, or zirconium(IV) chloride, were also able to promote the reaction, but ferrocenium tetrafluoroborate was the most efficient (Scheme $6)$. 


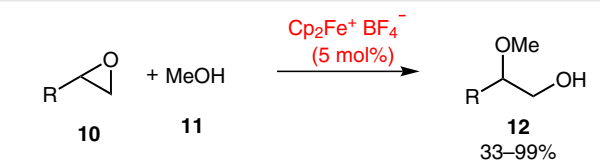

$\mathrm{R}=\mathrm{CICH}_{2}$, 2-naphthyl-OCH , Ph-O- $\mathrm{CH}_{2}, 4-\mathrm{O}_{2} \mathrm{~N}-\mathrm{C}_{6} \mathrm{H}_{4}-\mathrm{OCH}_{2}$, 4- $\mathrm{MeO}-\mathrm{C}_{6} \mathrm{H}_{4}-\mathrm{OCH}_{2}, \mathrm{C}_{10} \mathrm{H}_{21}$

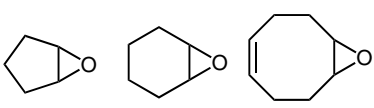

Scheme 6

\section{Ferrocenium Salts as One-Electron Oxi- dants}

Ferrocenium salts have been used to generate thioalkyl cations from 2-(tributylstannyl)-1,3-dithianes and 1(tributylstannyl)alkyl sulfides; the corresponding radicals reacted with olefinic nucleophiles. ${ }^{23}$ Ferrocenium salts were used for the oxidation of tetrakis(amino)benzenes to the corresponding dications. ${ }^{24}$ Ferrocenium ions also oxidize ketene silyl acetals and other organosilanes. ${ }^{25}$

Ferrocenium salts have been used extensively for decomplexation of dienetricarbonyliron complexes. ${ }^{26}$ As an example of this methodology, the synthesis of carbazole alkaloid mukonine (17), is presented (Scheme 7). ${ }^{27}$

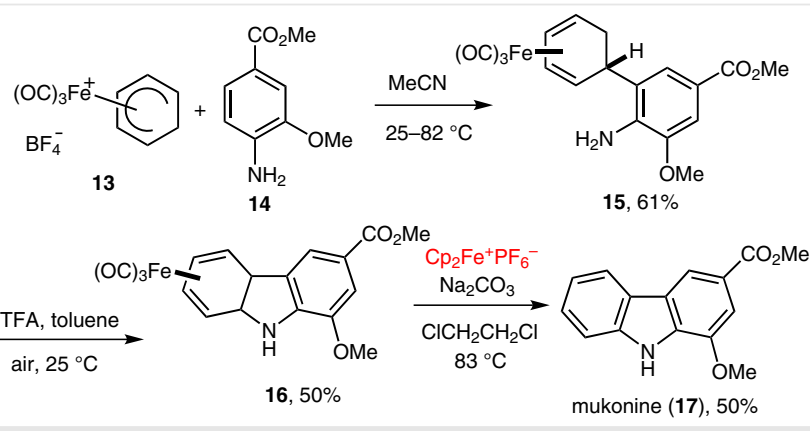

Scheme 7

An interesting application of a ferrocenium salt is in the synthesis of para-tert-butycalixarenes. ${ }^{28}$ The reaction of 4tert-butylphenol (18) and $s$-trioxane (19) in the presence of ferrocenium tetrafluoroborate afforded a mixture of the desired calixarenes 20. Catalysis by the ferrocenium ion led to much better results (57\% yield) than with Brønsted acid $(\mathrm{TsOH})$ catalyzed reactions. Even more importantly, the reaction was more selective, proceeding without the formation of undesired larger (10-20) calixarenes (Scheme 8). The mechanism of the reaction is unclear, but it is suggested that the ferrocenium ion participates in the one-electron oxidation of phenol to the phenoxy radical. Disappointingly, no such radical species were detected by EPR and no products of phenol dimerization were observed. However, the reaction did not proceed with O-alkylated phenols.

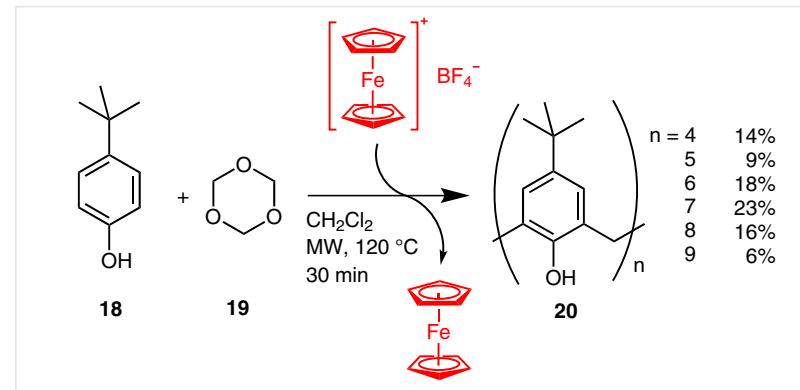

Scheme 8

The ferrocenium cation radical is most frequently used as a mild, one-electron oxidant of electron-rich species, such as enolate anions. The Jahn research group has focused extensively on this topic. They showed that alkenylmalonic esters 21 can be cyclized to bicyclic lactones $\mathbf{2 6}$ by intramolecular radical addition to the $\mathrm{C}=\mathrm{C}$ bond (Scheme 9). ${ }^{29}$ The reaction comprises of formation of the enolate $\mathbf{2 2}$, which is then oxidized by the ferrocenium ion to the corresponding radical $\mathbf{2 3}$, which then cyclizes to intermediate $\mathbf{2 4}$, and this is further oxidized to cation $\mathbf{2 5}$.
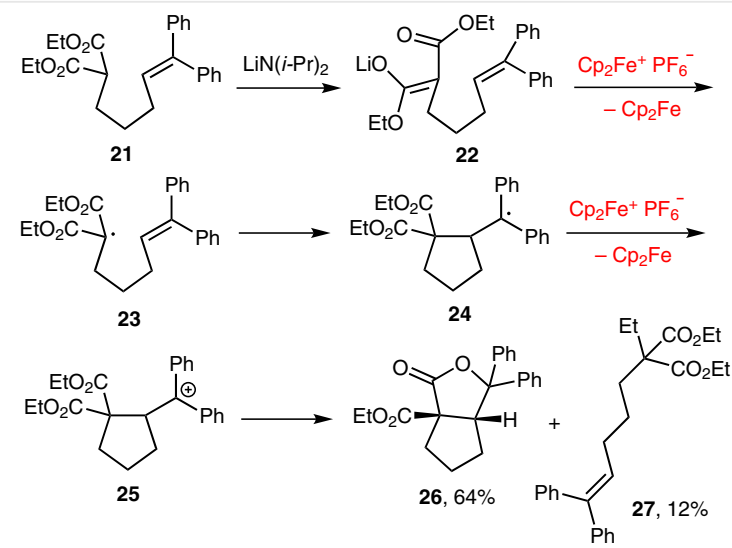

Scheme 9

Ferrocenium salts, such as ferrocenium hexafluorophosphate, were involved in the oxidation of the enolate anion to the corresponding radical as well as in the oxidation of cyclized radical to the corresponding carbenium ion. For this reason it was necessary to use 2.5 molar excess of ferrocenium salt in this reaction, but the majority of the ferrocene $(70-80 \%)$ was recovered after workup of the reaction mixture. The use of various bases, such as butyllithium, butylmagnesium bromide, lithium hexamethyldisilazanide, or lithium diisopropylamide, was examined for the generation of the starting ester enolate, but the best results were observed with lithium diisopropylamide. Several other oxidants have also been tested. For instance tris(4-bromophenyl)aminium hexachloroantimonate gave the corresponding lactone in just 32\%, whereas ammonium cerium(IV) nitrate and manganese(III) acetate were not effective. 
Intramolecular cyclization of $\omega$-silylallyl esters $\mathbf{2 8}$ was used for the synthesis of cyclopentanoid monoterpenes, such as dihydronepetalactone (32) (Scheme 10). ${ }^{30}$ In this transformation, the initially formed enolate 29 reacted with ethyl chloroformate to afford intermediate $\mathbf{3 0}$, which was then cyclized by the action of the ferrocenium ion to cyclopentane derivative 31 .
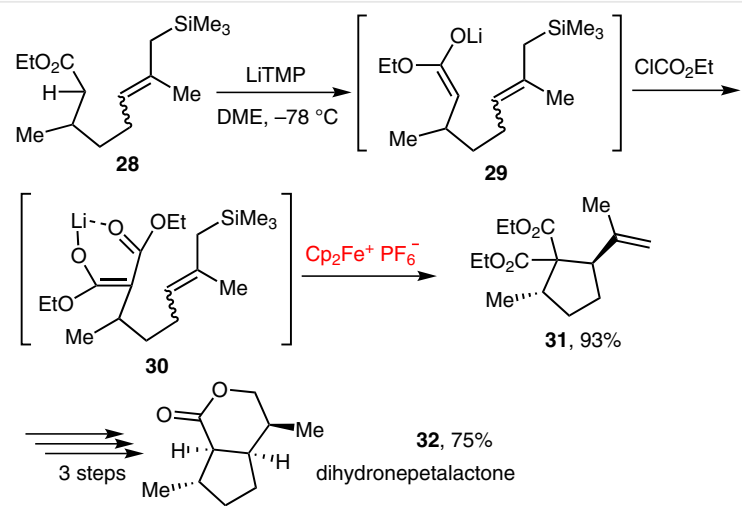

Scheme 10

Jahn and co-workers investigated an alkylation of diethyl malonate with pent-4-enyl halides, tosylates, and mesylates as means of producing the corresponding diethyl 2-(pent-4-enyl)malonates for oxidative cyclization; ${ }^{31}$ the alkylation was most effective if $20 \mathrm{~mol} \%$ of sodium iodide was added to the preformed diethyl malonate carbanion in a tetrahydrofuran- $N, N$-dimethylformamide mixture. The use of several bases and oxidants was examined in the oxidative cyclization of diethyl 2-(pent-4-enyl)malonate 33. Lithium diisopropylamide again proved to be the best base for this transformation. As for oxidant, apart from ferrocenium hexafluorophosphate, similar results were achieved using copper(II) chloride. Being solid, both oxidants required portionwise addition to the preformed lithium enolate ion (Scheme 11).

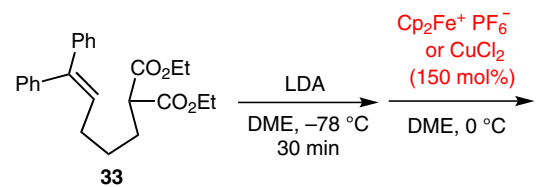

$64 \%$ with $\mathrm{Cp}_{2} \mathrm{Fe}^{+} \mathrm{PF}_{6}^{-}$ $69 \%$ with $\mathrm{CuCl}_{2}$

Scheme 11

The Jahn group trapped the intermediate radicals with 2,2,6,6-tetramethylpiperidin-1-oxyl radical (TEMPO). The first paper in this series described the synthesis of $\alpha$-hydroxy esters. ${ }^{32}$ Enolates generated using lithium diisopropylamide from the corresponding esters $\mathbf{3 5}$ were oxidized by ferrocenium hexafluorophosphate and the resulting rad- icals 36 were trapped with TEMPO at $-78{ }^{\circ} \mathrm{C}$. 2,2,6,6-Tetramethylpiperidin-1-yloxy adducts 37 , which were formed in good yields, were usually accompanied by small amount of dimerization product 38 . The initially used reaction conditions gave a complicated mixture of compounds, but modification of these conditions by the addition of six equivalents of hexamethylphosphoramide to the lithium diisopropylamide prior to enolate formation considerably improved results (Scheme 12). The adducts $\mathbf{3 7}$ were then transformed into corresponding hydroxy derivatives $\mathbf{3 9}$ by reduction with zinc in acetic acid.

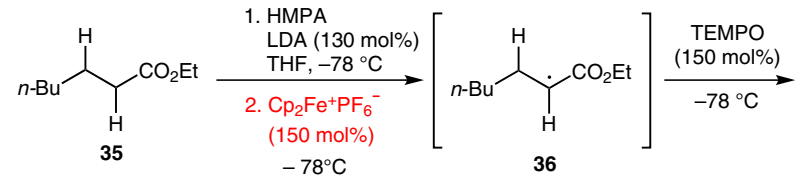

$$
\begin{aligned}
& \text { 瓜, } \\
& \mathrm{CtO}_{2} \mathrm{C}=\mathrm{C}_{5} \mathrm{CO}_{21} \mathrm{Et} \\
& \text { 38, } 25 \%
\end{aligned}
$$

Scheme 12

Similar reactions were performed with seven different esters. The formation of a radical intermediate is supported by the formation of up to $73 \%$ of dimeric product as a mixture of meso and $d / l$ isomers when TEMPO was not added to the reaction mixture. This methodology was later utilized in the synthesis of functionalized pyrrolidines. ${ }^{33}$ Michael addition of lithium amides $\mathbf{4 1}$ to $\alpha, \beta$-unsaturated esters $\mathbf{4 0}$ afforded derivatives $\mathbf{4 2}$, which served as the starting materials for ferrocenium-promoted radical cyclization to pyrrolidines 43. Small amounts (5-11\%) of acyclic side product 44 were also isolated (Scheme 13).

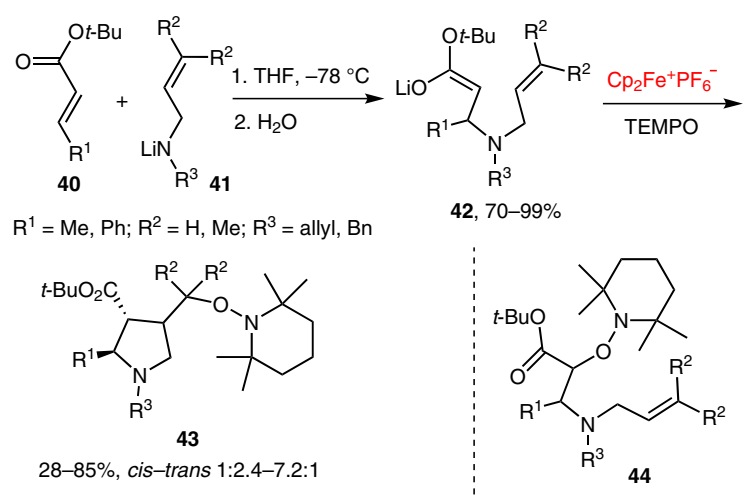

Scheme 13 
This methodology was used also for the cyclization of intermediates $\mathbf{4 5}$ to functionalized cyclopentanes $\mathbf{4 6}$ (Scheme 14) in a model synthesis for prostaglandins. ${ }^{34}$ Interestingly, the reactions worked well if an additional donor group was present on the skeleton. On the other hand, no cyclization was observed if there was an electron-withdrawing group near the reacting centers (Scheme 14).

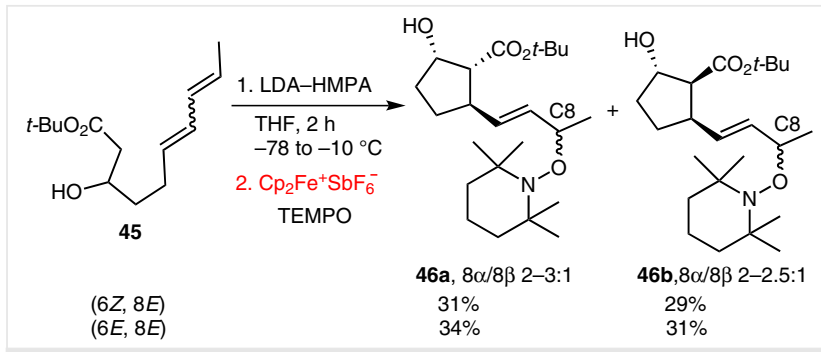

Scheme 14

The Jahn group have described the hydroxylation of a broad range of carbonyl compounds using this strategy. ${ }^{35}$ The previously developed methodology was modified by altering the order of addition of ferrocenium salt and TEMPO. The TEMPO was added to the enolate solution in one portion at $-78{ }^{\circ} \mathrm{C}$ and this was followed by the addition of solid ferrocenium hexachlorophosphate in small portions at a rate corresponding with its consumption, which was monitored by disappearance of the blue color of the reaction mixture. In this way, various esters, amides, nitriles, and ketones were hydroxylated in the $\alpha$-position. The reaction conditions were optimized for the hydroxylation of ethyl heptanoate and it was found that lower amounts of the radical dimers were formed when hexamethylphosphoramide or lithium chloride were added to the enolate solution.

Hydroxylation of a range of structurally diverse derivatives 47 with electron-withdrawing groups afforded the corresponding 2,2,6,6-tetramethylpiperidin-1-yloxy adducts 48 (Scheme 15).

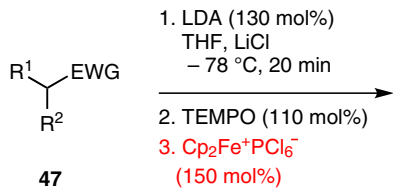

$\mathrm{R}^{1}=\mathrm{Me}, \mathrm{Et}, i-\mathrm{Pr}, n$-Pent, $\mathrm{C}_{6} \mathrm{H}_{13}, c-\mathrm{C}_{3} \mathrm{H}_{5}, \mathrm{Ph}, \mathrm{CO}_{2} \mathrm{Me}$

$\mathrm{R}^{2}=\mathrm{H}, \mathrm{Me}$

$\mathrm{EWG}=\mathrm{CO}_{2} \mathrm{Me}, \mathrm{CO}_{2} \mathrm{Et}, \mathrm{CO}_{2} t-\mathrm{Bu}, \mathrm{CN}, \mathrm{CONBn}_{2}, \mathrm{CONMe}_{2}$

Scheme 15

Even lactams can be successfully hydroxylated. The hydroxylation of $N$-methylpyrrolidin-2-one gave the $\alpha$-hydroxylated product in $57 \%$ yield. The hydroxylation of chiral
(S)-N-Boc-pyrroglutamate $\mathbf{4 9}$ worked well and more importantly it proceeded with complete conservation of stereogenic information at C2 of the product $\mathbf{5 0}$ (Scheme 16).

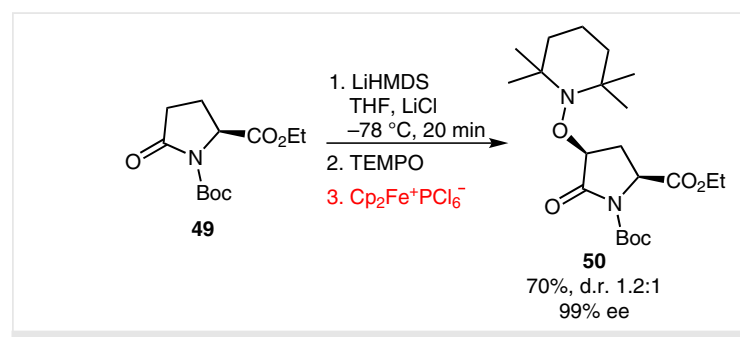

Scheme 16

The Jahn group also attempted $\alpha$-hydroxylation of free heptanoic acid, but they obtained the hydroxylated product in only $51 \%$ yield together with the dimers (14\%) and hept2-enoic acid (9\%). On the other hand, hydroxylation of various acyclic as well as cyclic ketones $\mathbf{5 1}$ proceeded very well. The corresponding products $\mathbf{5 2}$ were obtained in good yields. Only in the case of alkyl phenyl ketones was the hydroxylation accompanied by the formation of larger amounts of the corresponding dimers $\mathbf{5 3}$ (Scheme 17).

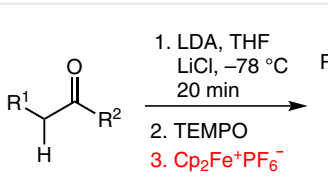

51

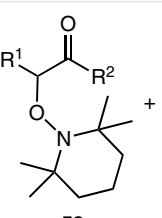

52

$90 \%$

$77 \%$

$84 \%$

$78 \%$<smiles>[R]OC([R])C([R])C([R])[R]</smiles>

53

$-$

$-$

$21 \%$
Scheme 17

Trisubstituted pyrrolidines were assembled by electrontransfer-induced oxidative cyclizations of $N$-allyl $\beta$-amino ester enolates. ${ }^{36}$

The Jahn group has improved the conditions for this type of anion-radical reaction. ${ }^{37}$ It was realized that ferrocene and 2,2,6,6-tetramethyl-1-oxopiperidinium hexafluorophosphate is in equilibrium with the corresponding ferrocenium salt and the equilibrium is shifted towards the ferrocenium ion. Therefore, they used only small amount of ferrocene (1-5 mol\%) and added the TEMPO salt to the mixture of a chiral lithium amide $\mathbf{5 4}$ and unsaturated ester $\mathbf{4 0}$. Under these conditions, tandem aza-Michael/radical cyclization proceeded and afforded densely functionalized pyrrolidines $\mathbf{5 5}$ (Scheme 18). 


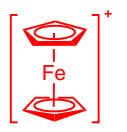<smiles>C=CC#CCC1(C)CCCC(C)(C)N1Oc1ccccc1</smiles>
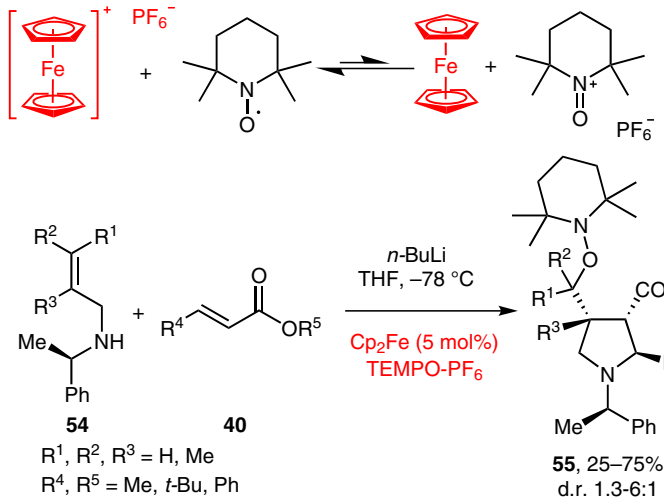<smiles>CC1(C)CCCCC1</smiles>

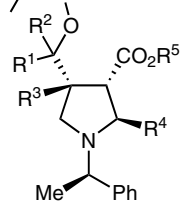

55, 25-75\% d.r. $1.3-6: 1$

Scheme 18

The Jahn group have developed an ingenuous route to metal enolates. These species were generated by organometallic addition to $\alpha, \beta$-unsaturated aldehydes, which afforded allylic alcoholates that were isomerized by ruthenium catalysis. Enolates formed in this way underwent addition to Michael acceptors followed by radical cyclization and oxygenation with TEMPO. ${ }^{38}$ These methodologies were applied to the syntheses of natural products, such as isoprostanes. ${ }^{39}$

Oxidative enolate dimerization promoted by the ferrocenium ion has been applied in the synthesis of the lomaiviticin family of natural products, which display potent cytotoxic activity. ${ }^{40}$ Ferrocenium hexachlorophosphate has also been used in an oxidative coupling of enolates of 3phenylpropanoic acid derivatives leading to synthesis of ent-hinokinon. However, the ferrocenium ion was a less effective oxidant in this case than other oxidants, such as iodine or copper(II) pentanoate. ${ }^{41}$

The direct coupling of pyrroles with carbonyl compounds under oxidative conditions has been reported. Copper salts, such as copper(II) 2-ethylhexanoate were the most efficient for this transformation. ${ }^{42}$ However, in the short synthesis of $(S)$-ketorolac (59), only ferrocenium hexafluorophosphate was able to mediate intramolecular coupling (Scheme 19). ${ }^{43}$

Bis-sulfinyl radicals $\mathbf{6 0}$ can also participate in radical cyclizations and TEMPO trapping to give 3,3-bis-sulfinyl tetrahydrofuran 61 (Scheme 20). ${ }^{44}$

Ferrocenium/TEMPO methodology was applied in the total synthesis of fusarisetin A, a metabolite from Fusarium fungi with considerable anticancer activity. ${ }^{45}$

This methodology has been utilized in the synthesis of bulky nitroxides and alkoxyamines derived from TEMPO. These compounds were used as initiators/regulators in the controlled radical polymerization of butyl acrylate and styrene. ${ }^{46}$

As previously discussed, small amounts of intermediate radical dimerization products were formed in the hydroxylation of different carbonyl derivatives. In attempts to oxida-

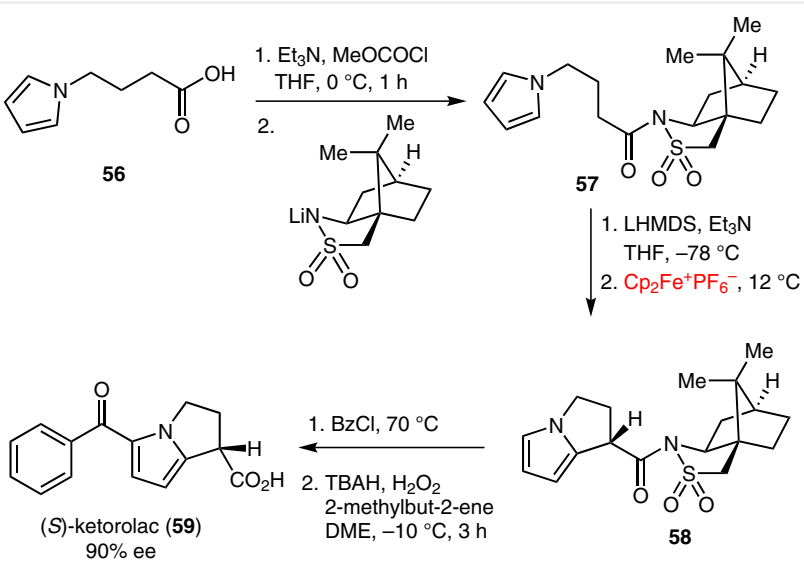

Scheme 19

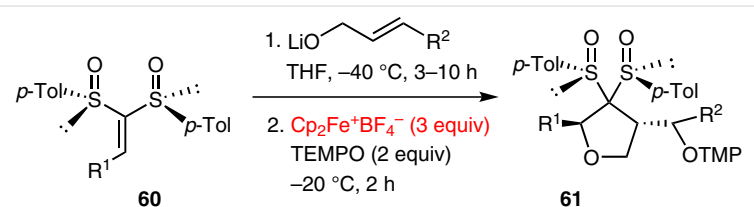

$\mathrm{R}^{1}=\mathrm{Ph}, 2-(\mathrm{PhO})-\mathrm{C}_{6} \mathrm{H}_{4}, i-\mathrm{Pr}$

$\mathrm{R}^{1}=2-(\mathrm{PhO})-\mathrm{C}_{6} \mathrm{H}_{4}, \mathrm{R}^{2}=\mathrm{H}, 56 \%$ $\mathrm{R}^{1}=\mathrm{Ph}, \mathrm{R}^{2}=\mathrm{H}, 59 \%$ $\mathrm{R}^{1}=i-\mathrm{Pr}, \mathrm{R}^{2}=\mathrm{H}, 41 \%$ $\mathrm{R}^{1}=\mathrm{Ph}, \mathrm{R}^{2}=\mathrm{Ph}, 48 \%$, dr 1.1:1

\section{Scheme 20}

tive couple the titanium enolate of 3-(phenylacetyl)oxazolidin-2-one (62), ${ }^{47}$ to achieve stereoselective coupling the reaction was performed in the presence of chiral ligands. The best results were achieved when TADDOL was used as the ligand, which gave the dimer $\mathbf{6 3}$ in $91 \%$ yield and $76 \%$ ee (Scheme 21).

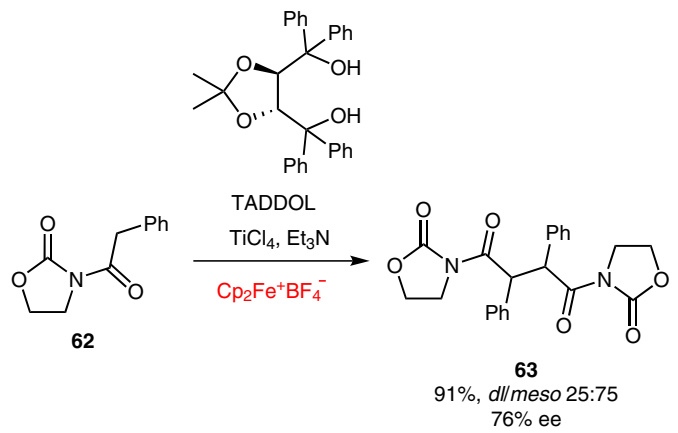

Scheme 21

An interesting discussion has evolved around presumed role of the ferrocenium ion in organo-SOMO activated reactions. Ferrocenium salts have been used in the organocatalytic $\alpha$-oxyamination of aldehydes (Scheme 22 ). ${ }^{48}$ The reaction was accelerated by pyrrolidine and MacMillan's oxazolidinone organocatalysts, in which case high stereoselectivity was observed. The reaction was initially assumed to proceed via MacMillan's SOMO pathway, in 
which ferrocenium ion was believed to oxidize the enamine intermediate. Later, MacMillan showed that this reaction does not proceed via the SOMO activation pathway, but rather via enamine activation. ${ }^{49}$ The rate-determining step of the process is the addition of TEMPO to the enamine and this adduct is then oxidized by $\mathrm{Fe}^{3+}$ ions forming an iminium cation that is finally hydrolyzed to the product. The activity of the ferrocenium ion in this transformation was explained by its decomposition to $\mathrm{Fe}^{3+}$ in $\mathrm{N}, \mathrm{N}$-dimethylformamide, which activated TEMPO for the addition.

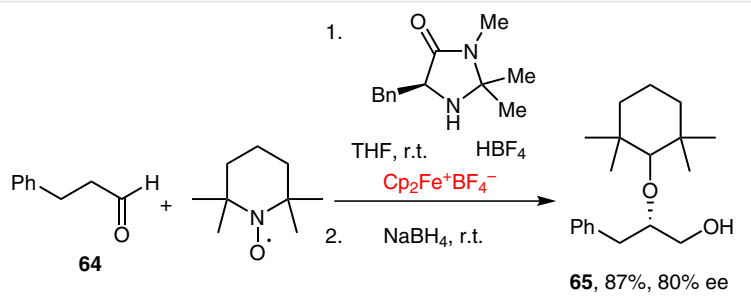

Scheme 22

Ferrocenium tetrafluoroborate was used as a co-catalyst to control Kumada coupling activity via a redox-active Nheterocyclic carbene. The catalyst was a cobaltocenium salt and the ferrocenium ion acted as re-oxidant for cobaltocene. $^{50}$

\section{Ferrocene as an Electron Donor}

Various reactions are promoted by ferrocene, which donates an electron to a substrate or reagent. This process generates the ferrocenium ion in situ, which often participates in another redox process. Ferrocene co-catalysis in a metal-catalyzed living radical polymerization of methyl methacrylate has been described. ${ }^{51}$ In this reaction, ferrocene was oxidized to the ferrocenium ion by a ruthenium(III) catalyst, namely $\mathrm{RuCl}\left(\mathrm{Cp}^{*}\right)\left(\mathrm{PPh}_{3}\right)_{2}$. The addition of ferrocene enabled significantly lower ruthenium catalyst loading. Furthermore, the reaction afforded the corresponding polymer with a low distribution of molecular weights. In the photodecomposition of chloroform by ferrocene/ferrocenium ion, ${ }^{52}$ ferrocene is photo-oxidized to the ferrocenium ion, which then decomposed chloroform to $\mathrm{HCl}, \mathrm{Cl}_{3} \mathrm{COOH}$, and $\mathrm{C}_{2} \mathrm{Cl}_{6}$. The addition of ferrocene catalyzed the degradation of methylene blue under Fenton conditions: ${ }^{53}$ ferrocene in this reaction was oxidized to the ferrocenium ion by hydrogen peroxide.

Ferrocene also promotes the addition of 2,2-dichlorocarboxylates to alk-1-enes. The role of ferrocene is to generate the corresponding alkyl radical by homolytic cleavage of the $\mathrm{C}-\mathrm{Cl}$ bond. ${ }^{54} \mathrm{~A}$ similar effect for ferrocene (acceleration of radical formation) was observed in the (ethoxycarbonyl)difluoromethylation of aromatic and heteroaromatic de- rivatives. Interestingly, ferrocene was a better catalyst than iron(II) sulfate. An example is the reaction of 2-acetyl-1methyl-1H-pyrrole (66) to give ethyl (5-acetyl-1-methyl$1 H$-pyrrol-2-yl)difluoroacetate (67) (Scheme 23). ${ }^{55}$

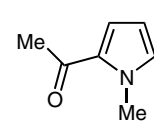

66

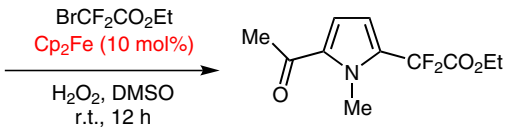

$67,88 \%$
Scheme 23

Ferrocene is a useful initiator for the decomposition of arenediazonium salts to aryl radicals. . $^{5,57}$

Meerwein arylation of ethyl vinyl ether with arenediazonium salts 69 using substoichiometric amounts of ferrocene promotes decomposition of the arenediazonium salts to aryl radicals, which then undergo addition to the double bond of ethyl vinyl ether. This transformation afforded a range of monoarylated acetaldehydes $\mathbf{7 0}$ in good yields. Furthermore, whole process was advantageously performed in a flow system (Scheme 24). ${ }^{58}$

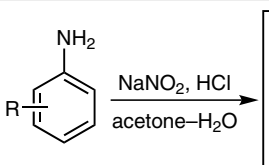

68

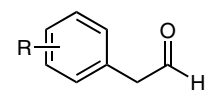

70, $59-76 \%$

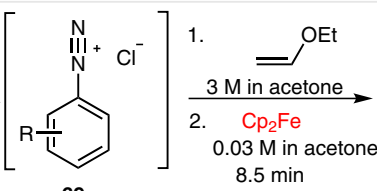

69

$\mathrm{R}=\mathrm{F}, \mathrm{Cl}, \mathrm{Br}, \mathrm{I}, \mathrm{CF}_{3}, \mathrm{CN}$, $\mathrm{CO}_{2} t-\mathrm{Bu}, \mathrm{NO}_{2}, \mathrm{OMe}, \mathrm{OCF}_{3}$, $\mathrm{OPh}$ (in various positions)
Scheme 24

Addition of ferrocene substantially accelerate RAFT polymerization of methyl methacrylate with 2-cyanoprop-2yl naphthalene-1-carbodithioate (CPDN). ${ }^{59}$

A mesoporous phenylene-silica that was derivatized with ferrocene catalyzed the oxidation of styrene to benzaldehyde. ${ }^{60}$ Apart from the main product, styrene oxide, 1phenylethanol and benzoic acid were found as side products. Hydrogen peroxide or tert-butyl hydroperoxide were, in this case, used as the oxidants. The reaction started with oxidation of ferrocene to a ferrocenium ion. The oxidation of different alkylbenzenes $\mathbf{7 1}$ and secondary alcohols $\mathbf{7 3}$ and $\mathbf{7 5}$ by $30 \%$ aqueous hydrogen peroxide was catalyzed either by ferrocene Schiff base anchored on polymer $\mathbf{C 1}$ or by its iron(III) chloride complex C2. ${ }^{61}$ Schiff base complex C2 was a much better catalyst. Presumably, the actual catalyst of the reaction was the ferrocenium ion, which was again formed by the oxidation of the ferrocenyl moiety in the Schiff base by hydrogen peroxide (Scheme 25). 


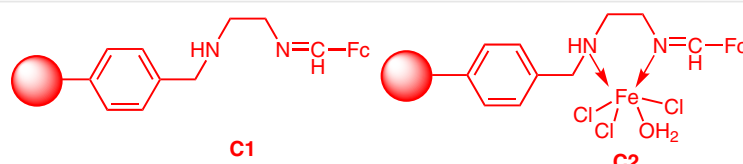

C1 c2<smiles>[R]Cc1ccc([X])cc1</smiles><smiles>[R]C(=O)c1ccc([X])cc1</smiles><smiles>[X]c1ccc(CO)cc1</smiles>

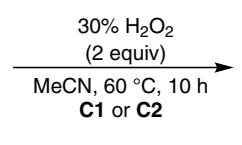
$\mathrm{X}=\mathrm{H}, \mathrm{Cl}, \mathrm{NO}_{2}$<smiles>[X]c1ccc(C=O)cc1</smiles>

$$
\sum_{\mathrm{R}^{2}}^{\mathrm{R}_{\mathbf{7 5}}} \stackrel{\begin{array}{c}
30 \% \mathrm{H}_{2} \mathrm{O}_{2} \\
(2 \text { equiv) }
\end{array}}{\begin{array}{c}
\mathrm{MeCN}, 60^{\circ} \mathrm{C}, 10 \mathrm{~h} \\
\mathbf{C 1} \text { or } \mathbf{C 2}
\end{array}}
$$

$$
\begin{aligned}
& \mathrm{R}_{\mathrm{R}^{2}}^{\mathrm{R}^{1}=0} \\
& 21-29 \%(\mathbf{C} 1) \\
& 68-86 \%(\mathbf{C} 2)
\end{aligned}
$$

\section{Scheme 25}

Ferrocenium salts were involved also in N-demethylation of $\mathrm{N}$-methylalkaloids (Figure 1 ). This reaction was catalyzed by ferrocene and some of its derivatives. ${ }^{62}$ The catalyst loading was usually between $20-25 \mathrm{~mol} \%$ of the ferrocene derivative and the best results were achieved when reactions were carried out in chloroform, or in the case of less soluble $\mathrm{N}$-methylalkaloid $\mathrm{N}$-oxides in chloroform-propan-2-ol (3:1) mixture at $50^{\circ} \mathrm{C}$. The most effective catalyst was ferrocenylacetic acid. The corresponding demethylation products were isolated in $72-86 \%$ yields.

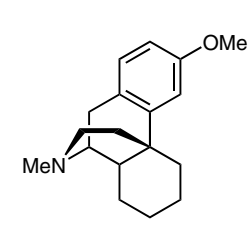

dextromethorphan
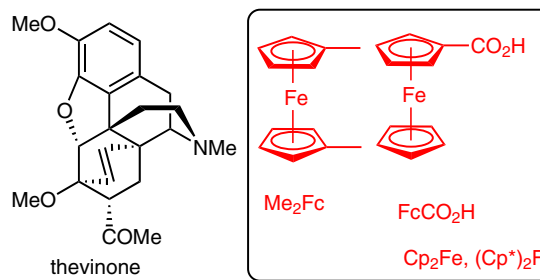

$\mathrm{FCCO}_{2} \mathrm{H}$

$\mathrm{Cp}_{2} \mathrm{Fe},\left(\mathrm{Cp}^{*}\right)_{2} \mathrm{Fe}$

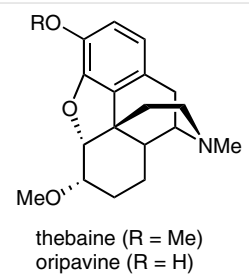

Figure $1 \mathrm{~N}$-Methylalkaloids studied in ferrocene-catalyzed demethylation

The demethylation reaction was also studied on the amine $\mathrm{N}$-oxides 77 . The reaction was performed as a onepot procedure, which comprised oxidation of alkaloids with

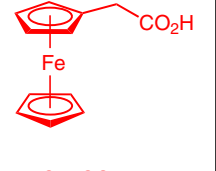
$\mathrm{FCCH}_{2} \mathrm{CO}_{2} \mathrm{H}$ $m$-chloroperoxybenzoic acid followed by the addition of the ferrocene derivative. The key step in the proposed mechanism is reduction of hydroxylammonium species $\mathbf{7 8}$ to Ncentered cation radical $\mathbf{8 0}$, and then oxidation of $\alpha$-aminyl radical $\mathbf{8 1}$ to iminium intermediate $\mathbf{8 2}$, which upon hydrolysis gave demethylated product 83 . Deoxygenated $N$-methylamines $\mathbf{8 4}$ were also observed (Scheme 26).

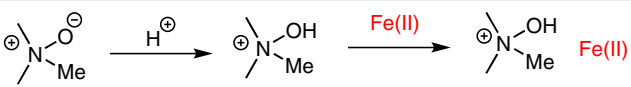

$$
\begin{aligned}
& 77 \quad \downarrow^{78} \quad \mathrm{H}^{\oplus}
\end{aligned}
$$

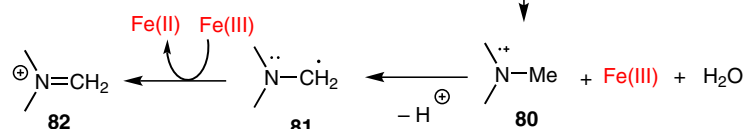

$$
\begin{aligned}
& \begin{array}{llll}
82 & 81 & -\mathrm{H} & 80
\end{array} \\
& \text { hydrolysis } \\
& \text { N-H+O=CH} \\
& 83 \\
& \underset{\mathrm{Fe}(\mathrm{III})}{\mathrm{Fe}(\mathrm{II})}
\end{aligned}
$$

Scheme 26

The ferrocenium cation was involved in the direct alkenylation of a $\mathrm{sp}^{3}(\mathrm{C}-\mathrm{H})$ bond by decarboxylation of cinnamic acids 85 and 87 under ligand-free conditions. ${ }^{63}$ The corresponding alkenyl products $\mathbf{8 6}$ and $\mathbf{8 8}$ were obtained in good yields. The mechanism comprises of the formation of benzyl radicals, which add to the double bond of the cinnamic acid, followed by decarboxylation and oxidation of the intermediary radical (Scheme 27).

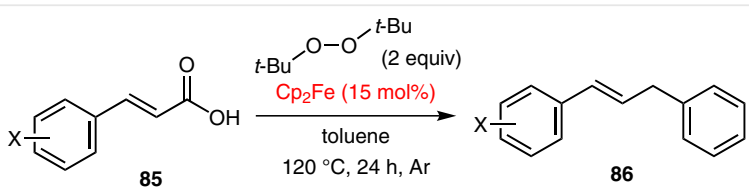

$\mathrm{X}=\mathrm{H}, \mathrm{Cl}, \mathrm{F}, \mathrm{OMe}, \mathrm{Me} 63-86 \% \quad \mathrm{X}=\mathrm{NO}_{2}, \mathrm{CN}, \mathrm{COOMe} 21-45 \%$ instead of phenyl can be 2-furyl , 2-thienyl, 3-pyridyl, 1-naphthyl $78-85 \%$

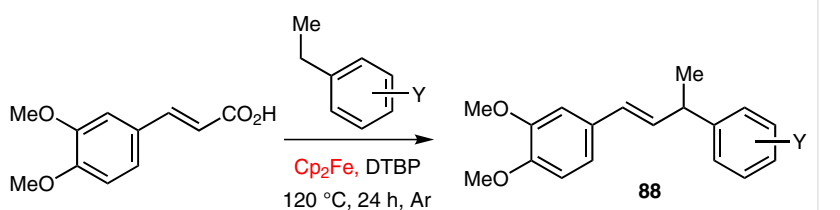
$120^{\circ} \mathrm{C}, 24 \mathrm{~h}, \mathrm{Ar} \quad \mathrm{Y}=\mathrm{Cl}, \mathrm{I}, \mathrm{COMe}, \mathrm{CH}_{2} \mathrm{Cl}$, etc.

$$
\begin{aligned}
& 8760-80 \% \\
& \mathrm{ArMe}+\frac{\gamma}{} \longrightarrow \mathrm{ArCH}_{2}
\end{aligned}
$$

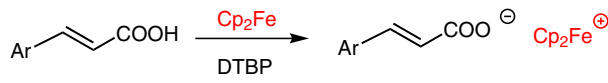

$$
\begin{aligned}
& \stackrel{\mathrm{ArCH}_{2}{ }_{\mathrm{Ar}} \overbrace{\mathrm{COO}^{\Theta}}^{\mathrm{Ar}} \mathrm{Cp}_{2} \mathrm{Fe}}{\oplus} \underset{\substack{-\mathrm{CO}_{2} \\
-\mathrm{Cp}_{2} \mathrm{Fe}}}{\longrightarrow} \mathrm{Ar} \curvearrowright \mathrm{Ar}_{\mathrm{Ar}}
\end{aligned}
$$

Scheme 27 
Participation of the ferrocenium salt was proposed for the ferrocene-catalyzed synthesis of arylboronic acids from arenediazonium salts (Scheme 28). ${ }^{64}$ Arenediazonium tetrafluoroborates $\mathbf{8 9}$ were treated with ferrocene and an aminoborane. Intermediary aryl(amino)boranes $\mathbf{9 0}$ were then transformed into pinacol boronates 81. However, boronic acid, potassium trifluoroborate, or diaminonaphthylborane could also be obtained. Both electron-donating and electron-withdrawing groups were tolerated in the starting material and the product yield ranged from 60 to $70 \%$. The proposed reaction mechanism is shown in Scheme 29.

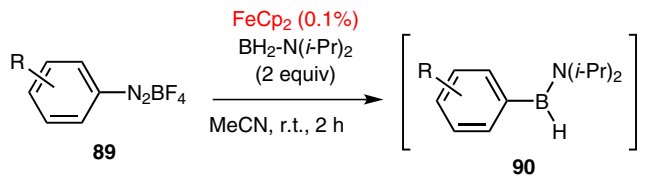

$\mathrm{R}=\mathrm{Me}, \mathrm{MeO}, \mathrm{NO}_{2}, \mathrm{~F}_{3} \mathrm{C}, \mathrm{F}, \mathrm{Cl}, \mathrm{Br}, \mathrm{I}$ (in various positions)

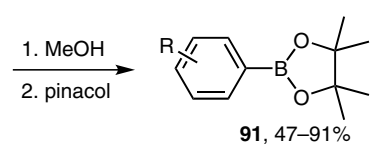

Scheme 28

$$
\begin{aligned}
& \mathrm{FeCp} p_{2}+\mathrm{ArN}_{2} \mathrm{BF}_{4} \longrightarrow \mathrm{Ar}^{*}+\left[\mathrm{Fe}^{\mathrm{III}} \mathrm{Cp}_{2}\right] \mathrm{BF}_{4}+\mathrm{N}_{2}
\end{aligned}
$$

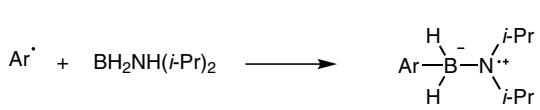

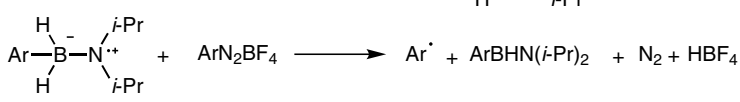

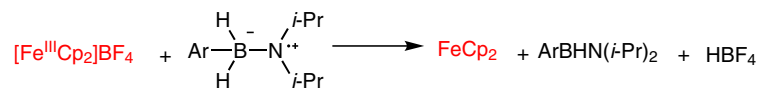

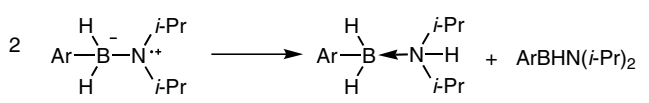

$$
\begin{aligned}
& {\left[\mathrm{Fe}^{\mathrm{III}} \mathrm{Cp}_{2}\right] \mathrm{BF}_{4} \underset{\text { or } \mathrm{ArBHN}(i-\mathrm{Pr})_{2}}{\stackrel{\mathrm{BH}_{2} \mathrm{NH}(i-\mathrm{Pr})_{2}}{\longrightarrow}} \mathrm{FeCp}_{2}}
\end{aligned}
$$

\section{Scheme 29}

A small amount of ferrocene can initiate the intramolecular cross dehydrogenative coupling of ortho-formylbiphenyls 92 or ortho-formyl diphenyl ethers $93 .^{65}$ The reaction occurs via base-mediated homolytic aromatic substitution and affords a range of xanthones 94 and fluorenones 95 in preparatively useful yields (Scheme 30 ).

Ferrocenium salt were involved in an interesting asymmetric dehydrogenative Heck reaction on [(dimethylamino)methyl]ferrocene (96). ${ }^{66}$ The reaction was catalyzed by palladium(II) acetate and chiral ligands, in this case mono-

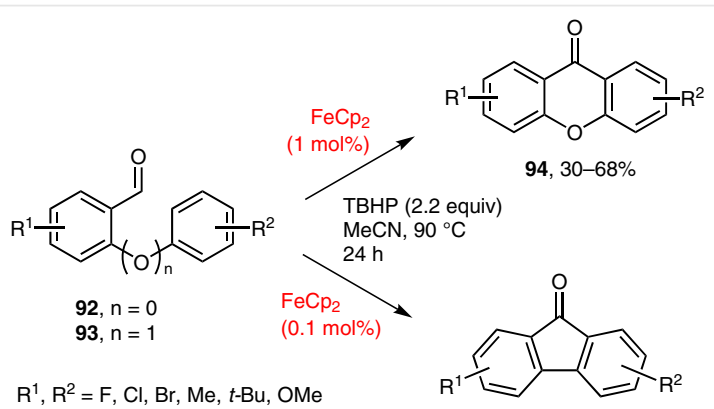

95, 56-84\%

Scheme 30

protected $\alpha$-amino acids. The reaction conditions were optimized with [(dimethylamino)methyl]ferrocene (96) and butyl acrylate (97) (Scheme 31).
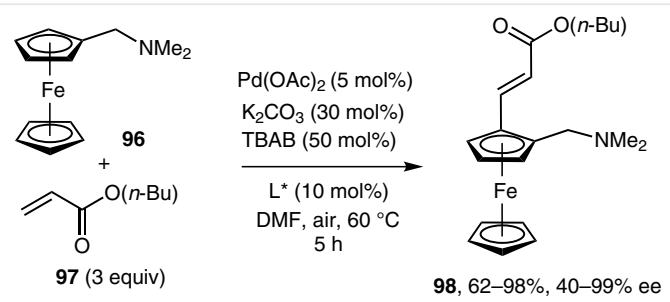

Scheme 31

The most efficient chiral ligands were Boc-protected tert-leucine, phenylalanine, leucine, or isoleucine (up to $98 \%$ yield and $99 \%$ ee). Seventeen different alkenes were examined in this reaction and in all cases, the corresponding products were isolated in high yield and enantiomeric purities. An important intermediate in the reaction is the [(dimethylamino)methyl]ferrocenium cation formed by air oxidation. It reoxidizes $\operatorname{Pd}(0)$ to $\operatorname{Pd}(\mathrm{II})$ and thus helps to close the catalytic cycle (Scheme 32 ). The formation of this intermediate is supported by a control experiment using $\mathrm{N}, \mathrm{N}$-dimethylbenzylamine as the substrate in air, which afforded only trace amounts of the desired product.

The involvement of a ferrocenium ion was proposed in the unexpected vinylic nucleophilic substitution of a fluoride anion by a hydroxide anion. ${ }^{67}$ The reaction occurred with 1,1'-bis(trifluorovinyl)ferrocene upon its oxidation by silica gel or potassium hexacyanoferrate(III).

Ferrocene can catalyze radical C-H imidation of (hetero)arenes 99.68 A range of aromatic and heteroaromatic compounds were derivatized in this way. The methodology tolerated both oxidizable, acid-labile functionalities, as well as multiple heteroatoms and aryl iodides (Scheme 33). 


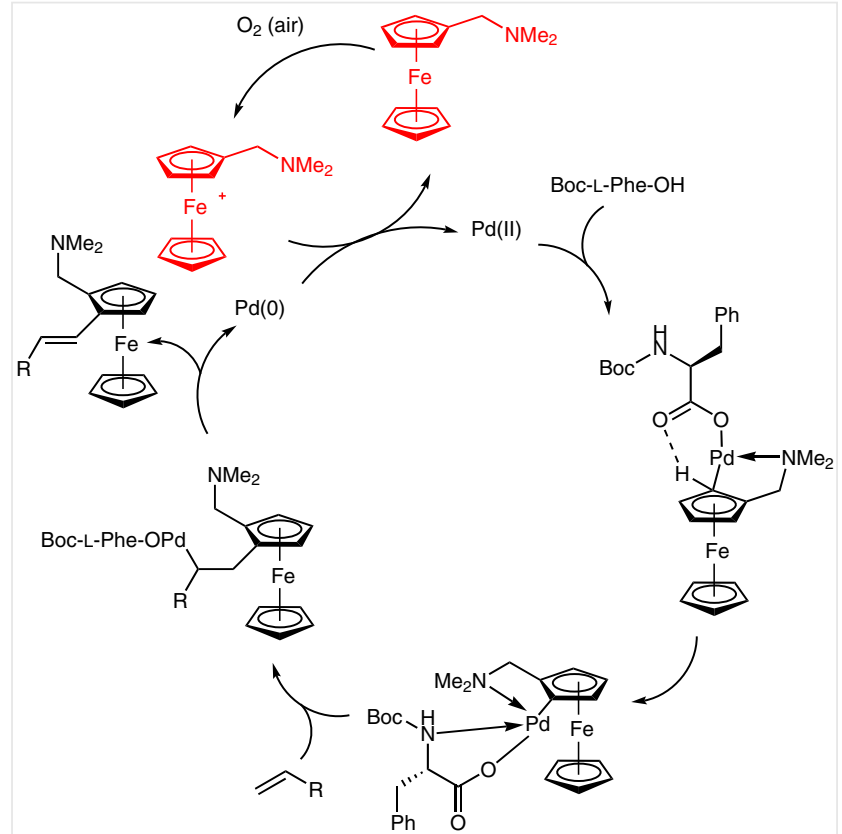

Scheme 32

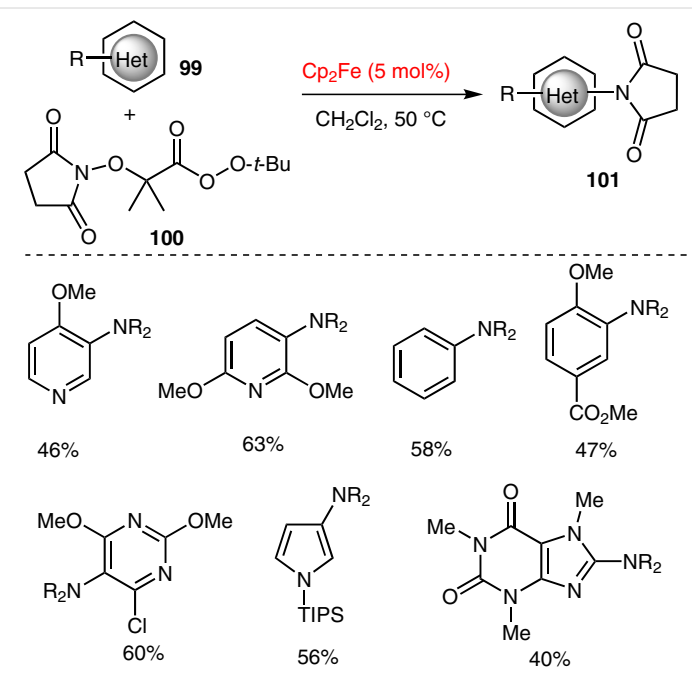

Scheme 33

Ferrocene functions as an electron shuttle in the decomposition of perester reagent 100; this decomposition affords succinimidyl radical 102, which adds to the aromatic system. Finally, the electron is removed by a ferrocenium ion from intermediary radical $\mathbf{1 0 3}$ to afford final products 101 (Scheme 34).

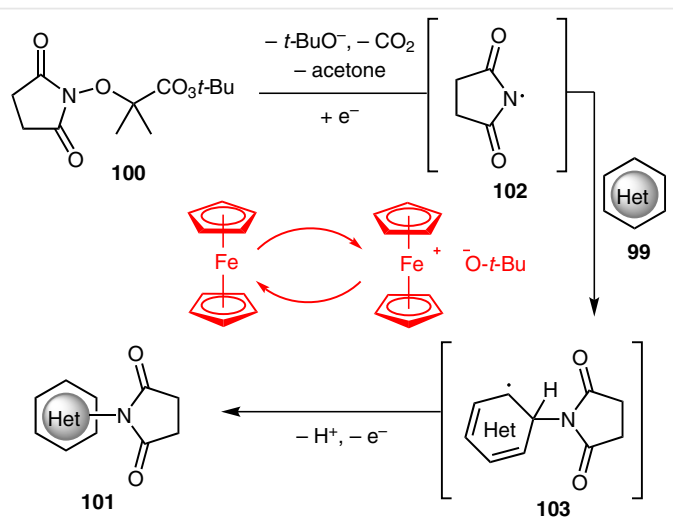

Scheme 34

Ferrocene can be used in the aryldifluoromethylation of activated alkenes 104 (Scheme 35). ${ }^{69}$ Ferrocene is first oxidized by hydrogen peroxide to the ferrocenium ion. By the action of hydroxyl radicals on dimethyl sulfoxide, methyl radicals were likely formed that help to generate the desired sulfonyldifluoromethyl radical. These species add to the conjugated double bond of the substrate and initiate the radical cyclization. In the last step, the ferrocenium ion oxidizes the intermediary radical to the product 105.

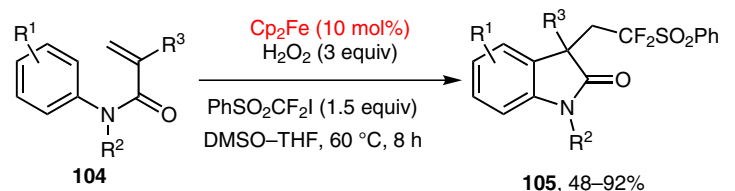

$\mathrm{R}^{1}=\mathrm{Me}, \mathrm{MeO}, \mathrm{F}, \mathrm{Cl}, \mathrm{Br}, \mathrm{I}, \mathrm{CF}_{3} \mathrm{O}, \mathrm{CF}_{3}$

$105,48-92 \%$

$\mathrm{R}^{2}=\mathrm{Me}, \mathrm{Bn}$

$\mathrm{R}^{3}=\mathrm{Me}, \mathrm{Bn}, \mathrm{CH}_{2} \mathrm{OMe}, \mathrm{CH}_{2} \mathrm{OAc}, \mathrm{CH}_{2} \mathrm{NPhth}$

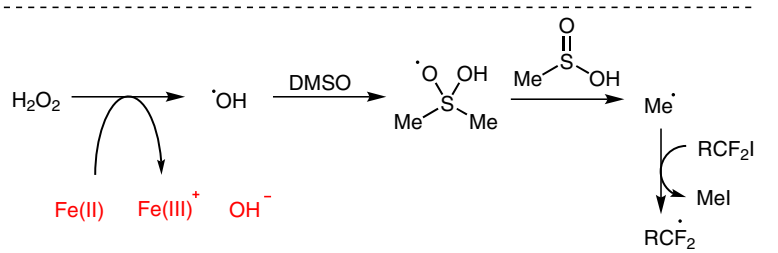

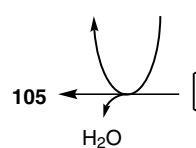

$\mathrm{H}_{2} \mathrm{O}$

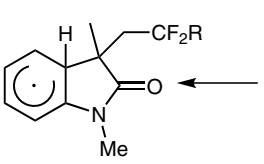

$\overbrace{\substack{I \\ \mathrm{Me}}} \overbrace{\mathrm{CF}_{2} \mathrm{R}}^{104}$
Scheme 35

\section{Catalysis with Other Ferrocenium Deriva- tives}

A SciFinder search for 'ferrocenium salts as catalyst' resulted in more than 50 references, mostly patents on photochemical initiation of oxirane and other monomers polymerization. Generally, these reactions use atypical ferrocenium salts, various iron complexes of the type $\left(\eta^{6}\right.$-arene $)\left(n^{5}\right.$ - 
cyclopentadienyl)iron(+). Such salts are produced by BASF, Ciba-Geigy, and Syngenta and are used in industry. For interested readers, several such structures are depicted in Figure $2 .{ }^{70}$

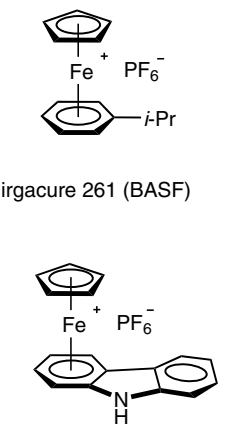

CFC

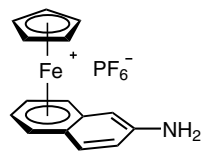

CFN

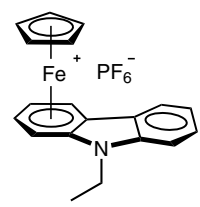

CFE
Figure 2

\section{Conclusions}

Ferrocenium salts have various uses in organic synthesis. The major application is connected with its suitable redox properties. Therefore, the ferrocenium ion is preferentially used as a mild, one-electron, oxidant for different carbanions or enolate ions. The corresponding radicals, which are formed in this way, enter into different radical reactions. The Lewis acidity of the ferrocenium ion is rather weak; nevertheless, there are several examples where the ferrocenium ion is employed as a Lewis acidic catalyst. The ferrocenium ion can activate an epoxide for ring opening or a carbonyl group for additions or cycloadditions. The ferrocenium ion participates in several reactions that are initiated by donation of an electron from ferrocene to the substrate and later the electron is accepted back by the ferrocenium ion.

The easy availability, low price, stability, and nontoxicity of ferrocenium salts makes them interesting reagent for various organic reactions that rely on redox transformations. We hope that this review will aid the synthetic organic community to devise other possible applications of ferrocenium salts.

\section{Acknowledgment}

Support from Slovak Grant Agency VEGA, grant no.: VEGA-1-0623-12 is gratefully acknowledged. We thank reviewers for valuable suggestions.

\section{References}

(1) Dai, L.-X.; Hou, X.-L. Chiral Ferrocenes in Asymmetric Catalysis; Wiley-VCH: Weinheim, 2010.
(2) Štepnička, P. Ferrocene: Ligands, Materials and Biomolecules; Wiley: Chichester, 2008.

(3) Gagne, R. R.; Koval, C. A.; Lisensky, G. C. Inorg. Chem. 1980, 19, 2854.

(4) Connelly, N. G.; Geiger, W. E. Chem. Rev. 1996, 96, 877.

(5) Rosenblum, M. Chemistry of the Iron Group Metallocenes: Ferrocene, Ruthenocene, Osmocene; Interscience Publishers: New York, 1965.

(6) Green, J. C. Gas Phase Photoelectron Spectra of $d$ - and f-Block Organometallic Compounds, In Bonding Problems; Vol. 43, 37-1; Springer: Berlin, 1981, 12.

(7) Wilkinson, G.; Rosenblum, M.; Whiting, M. C.; Woodward, R. B. J. Am. Chem. Soc. 1952, 74, 2125.

(8) Smart, J. C.; Pinsky, B. L. J. Am. Chem. Soc. 1980, 102, 1009.

(9) Gray, H. B.; Hendrickson, D. N.; Sohn, Y. S. Inorg. Chem. 1971, 10 , 1559.

(10) Steffen, P.; Unkelbach, C.; Christmann, M.; Hiller, W.; Strohmann, C. Angew. Chem. Int. Ed. 2013, 52, 9836.

(11) Daeneke, T.; Mozer, A. J.; Kwon, T.-H.; Duffy, N. W.; Holmes, A. B.; Bach, U.; Spiccia, L. Energy Environ. Sci. 2012, 5, 7090.

(12) Khobragade, D. A.; Mahamulkar, S. G.; Pospíšil, L.; Císařová, I.; Rulíšek, L.; Jahn, U. Chem.-Eur. J. 2012, 18, 12267.

(13) Chávez, I.; Alvarez-Carena, A.; Molins, E.; Roig, A.; Maniukiewicz, W.; Arancibia, A.; Arancibia, V.; Brand, H.; Manríquez, J. M. J. Organomet. Chem. 2000, 601, 126.

(14) (a) Bradley, S.; Camm, K. D.; Liu, X.; McGowan, P. C.; Mumtaz, R.; Oughton, K. A.; Podesta, T. J.; Thornton-Pett, M. Inorg. Chem. 2002, 41, 715. (b) Furtado, S. J.; Gott, A. L.; McGowan, P. C. Dalton Trans. 2004, 436.

(15) Astruc, D. New J. Chem. 2011, 35, 764.

(16) Studer, A.; Curran, D. P. Nat. Chem. 2014, 6, 765.

(17) Kelly, T. R.; Maity, S. K.; Meghani, P.; Chandrakumar, N. S. Tetrahedron Lett. 1989, 30, 1357.

(18) (a) Locke, A. J.; Richards, C. J. Organometallics 1999, 18, 3750. (b) Gibis, K.-L.; Helmchen, G.; Huttner, G.; Zsolnai, L. J. Organomet. Chem. 1993, 445, 181.

(19) Khan, N.-u. H.; Agrawal, S.; Kureshy, R. I.; Abdi, S. H. R.; Singh, S.; Jasra, R. V. J. Organomet. Chem. 2007, 692, 4361.

(20) Khan, N.-u. H.; Agrawal, S.; Kureshy, R. I.; Abdi, S. H. R.; Singh, S.; Suresh, E.; Jasra, R. V. Tetrahedron Lett. 2008, 49, 640.

(21) Yadav, G. D.; Chauhan, M. S.; Singh, S. Synthesis 2014, 46, 629.

(22) Yadav, G. D.; Singh, S. Tetrahedron Lett. 2014, 55, 3979.

(23) Narasaka, K.; Arai, N.; Okauchi, T. Bull. Chem. Soc. Jpn. 1993, 66, 2995.

(24) Adams, C. J.; da Costa, R. C.; Edge, R.; Evans, D. H.; Hood, M. F. J. Org. Chem. 2010, 75, 1168.

(25) Fukuzumi, S.; Fujita, M.; Otera, J.; Fujita, Y. J. Am. Chem. Soc. 1992, 114, 10271.

(26) (a) Knölker, H.-J. Chem. Rev. 2000, 100, 2941. (b) Knolker, H. J.; Braier, A.; Brocher, D. J.; Cammerer, S.; Frohner, W.; Gonser, P.; Hermann, H.; Herzberg, D.; Reddy, K. R.; Rohde, G. Pure Appl. Chem. 2001, 73, 1075. (c) Bauer, I.; Knölker, H.-J. Synthesis of Pyrrole and Carbazole Alkaloids, In Alkaloid Synthesis; Vol. 309: 203-2; Springer: Heidelberg, 2012.

(27) Knölker, H.-J.; Wolpert, M. Tetrahedron Lett. 1997, 38, 533.

(28) Bew, S. P.; Cheesman, M. R.; Sharma, S. V. Chem. Commun. 2008, 5731.

(29) (a) Jahn, U.; Hartmann, P. Chem. Commun. 1998, 209. (b) Jahn, U.; Hartmann, P. J. Chem. Soc., Perkin Trans. 1 2001, 2277.

(30) Jahn, U.; Hartmann, P.; Kaasalainen, E. Org. Lett. 2004, 6, 257.

(31) Jahn, U.; Hartmann, P.; Dix, I.; Jones, P. G. Eur.J. Org. Chem. 2001, 3333.

(32) Jahn, U. J. Org. Chem. 1998, 63, 7130. 
(33) Jahn, U.; Müller, M.; Aussieker, S. J. Am. Chem. Soc. 2000, 122, 5212.

(34) Jahn, U.; Hartmann, P.; Dix, I.; Jones, P. G. Eur.J. Org. Chem. 2002, 718.

(35) Dinca, E.; Hartmann, P.; Smrček, J.; Dix, I.; Jones, P. G.; Jahn, U. Eur. J. Org. Chem. 2012, 4461.

(36) Jahn, U.; Kafka, F.; Pohl, R.; Jones, P. G. Tetrahedron 2009, 65, 10917.

(37) Kafka, F.; Holan, M.; Hidasová, D.; Pohl, R.; Císařová, I.; Klepetářová, B.; Jahn, U. Angew. Chem. Int. Ed. 2014, 53, 9944.

(38) Jagtap, P. R.; Ford, L.; Deister, E.; Pohl, R.; Císařová, I.; Hodek, J.; Weber, J.; Mackman, R.; Bahador, G.; Jahn, U. Chem.-Eur.J. 2014, $20,10298$.

(39) (a) Jahn, U.; Dinca, E. Chem.-Eur. J. 2009, 15, 58. (b) Jahn, U.; Dinca, E. J. Org. Chem. 2010, 75, 4480.

(40) (a) Krygowski, E. S.; Murphy-Benenato, K.; Shair, M. D. Angew. Chem. Int. Ed. 2008, 47, 1680. (b) Lee, H. G.; Ahn, J. Y.; Lee, A. S.; Shair, M. D. Chem.-Eur. J. 2010, 16, 13058. (c) Lee, A. S.; Shair, M. D. Org. Lett. 2013, 15, 2390.

(41) Langer, T.; Illich, M.; Helmchen, G. Synlett 1996, 1137.

(42) Richter, J. M.; Whitefield, B. W.; Maimone, T. J.; Lin, D. W.; Castroviejo, M. P.; Baran, P. S. J. Am. Chem. Soc. 2007, 129, 12857.

(43) Baran, P. S.; Richter, J. M.; Lin, D. W. Angew. Chem. Int. Ed. 2005, $44,609$.

(44) Goddard, J.-P.; Gomez, C.; Brebion, F.; Beauviere, S.; Fensterbank, L.; Malacria, M. Chem. Commun. 2007, 2929.

(45) (a) Xu, J.; Caro-Diaz, E. J. E.; Trzoss, L.; Theodorakis, E. A. J. Am. Chem. Soc. 2012, 134, 5072. (b) Xu, J.; Caro-Diaz, E. J. E.; Lacoske, M. H.; Hung, C.-I.; Jamora, C.; Theodorakis, E. A. Chem. Sci. 2012, 3, 3378.

(46) Jing, Y.; Mardyukov, A.; Bergander, K.; Daniliuc, C. G.; Studer, A. Macromolecules 2014, 47, 3595.

(47) Nguyen, P. Q.; Schäfer, H. J. Org. Lett. 2001, 3, 2993.

(48) Sibi, M. P.; Hasegawa, M. J. Am. Chem. Soc. 2007, 129, 4124.

(49) Van Humbeck, J. F.; Simonovich, S. P.; Knowles, R. R.; MacMillan, D. W. C. J. Am. Chem. Soc. 2010, 132, 10012.

(50) Tennyson, A. G.; Lynch, V. M.; Bielawski, C. W. J. Am. Chem. Soc. 2010, 132, 9420.

(51) Fujimura, K.; Ouchi, M.; Sawamoto, M. ACS Macro Lett. 2012, 1, 321.
(52) Peña, L. A.; Seidl, A. J.; Cohen, L. R.; Hoggard, P. E. Transition Met. Chem. (Dordrecht, Neth.) 2009, 34, 135.

(53) Wang, Q.; Tian, S.; Cun, J.; Ning, P. Desalin. Water Treat. 2013, 51, 5821.

(54) Forti, L.; Ghelfi, F.; Pagnoni, U. M. Tetrahedron 1997, 53, 4419.

(55) Ohtsuka, Y.; Yamakawa, T. Tetrahedron 2011, 67, 2323.

(56) Wassmundt, F. W.; Kiesman, W. F. J. Org. Chem. 1997, 62, 8304.

(57) Beckwith, A. L. J.; Jackson, R. A.; Longmore, R. W. Aust. J. Chem. 1992, 45, 857.

(58) Chernyak, N.; Buchwald, S. L. J. Am. Chem. Soc. 2012, 134, 12466.

(59) Chen, Q.; Zhang, Z.; Zhou, N.; Zhu, J.; Pan, Q.; Zhu, X. J. Polym. Sci., Part A: Polym. Chem. 2009, 47, 3607.

(60) Gomes, A. C.; Ferreira, M. J.; Bruno, S. M.; Bion, N.; Ferreira, P.; Valente, A. A.; Pillinger, M.; Rocha, J.; Goncalves, I. S. Dalton Trans. 2013, 42, 14612

(61) Islam, S.; Paul, S.; Roy, A.; Mondal, P. J. Inorg. Organomet. Polym. 2013, 23, 560 .

(62) (a) Kok, G. B.; Scammells, P. J. Bioorg. Med. Chem. Lett. 2010, 20 , 4499. (b) Kok, G. B.; Scammells, P. J. Synthesis 2012, 44, 2587.

(63) Yang, H.; Yan, H.; Sun, P.; Zhu, Y.; Lu, L.; Liu, D.; Rong, G.; Mao, J. Green Chem. 2013, 15, 976.

(64) Marciasini, L. D.; Richy, N.; Vaultier, M.; Pucheault, M. Adv. Synth. Catal. 2013, 355, 1083.

(65) Wertz, S.; Leifert, D.; Studer, A. Org. Lett. 2013, 15, 928.

(66) Pi, C.; Li, Y.; Cui, X.; Zhang, H.; Han, Y.; Wu, Y. Chem. Sci. 2013, 4, 2675.

(67) Roemer, M.; Lentz, D. Chem. Commun. 2011, 47, 7239.

(68) Foo, K.; Sella, E.; Thomé, I.; Eastgate, M. D.; Baran, P. S. J. Am. Chem. Soc. 2014, 136, 5279.

(69) Wang, J.-Y.; Zhang, X.; Bao, Y.; Xu, Y.-M.; Cheng, X.-F.; Wang, X.S. Org. Biomol. Chem. 2014, 12, 5582.

(70) (a) Wang, T.; Chen, J. W.; Li, Z. Q.; Wan, P. Y.J. Photochem. Photobiol., A 2007, 187, 389. (b) Catilaz-Simonin, L.; Fouassier, J. P. J. Appl. Polym. Sci. 2001, 79, 1911. (c) Lazauskaité, R.; Budreckiené, R.; Gražulevičius, J. V.; Abadie, M. J. M. J. Prakt. Chem. 2000, 342, 569. (d) Chen, Y.; Li, G.; Han, J.; Wang, T. J. Photochem. Photobiol., A 2011, 222, 330. (e) Wang, T.; Li, B. S.; Zhang, L. X. Polym. Int. 2005, 54, 1251. 